\title{
Evaluation of Ethambutol Toxic Optic Neuropathy Module as Training Approach for Tuberculosis Directly Observed Treatment Short-course Health Workers in Manila: A Pilot Study
}

\author{
Ryan Caezar C David ${ }^{1 *}$ and Vina P Ballado ${ }^{1,2}$ \\ ${ }^{1}$ Department of Ophthalmology, Ospital ng Maynila Medical Center, Philippines \\ ${ }^{2}$ Lecturer, College of Medicine, Pamantasan ng Lungsod ng Maynila, Philippines
}

*Corresponding author: Ryan Caezar C David, Department of Ophthalmology, Ospital ng

Received Date: June 25, 2019

Maynila Medical Center, Manila, Philippines.

Published Date: July 01, 2019

\section{Abstract}

Aim: To determine the effectiveness of the ethambutol toxic optic neuropathy (ETON) module as a training approach and to increase the competency of primary health workers in assessing the visual health of TB DOTS patients.

Methods: Thirty-six (36) TB DOTS sites in Manila were included in the evaluation and were randomly allocated into 2 groups. Group 1 was assigned as the treatment group, received the ETON module, and Group 2, the control group, was provided with information, education, and communication materials only. A questionnaire on knowledge, attitudes, and practices on vision screening was administered before and after intervention. An objective structured clinical examination (OSCE) was also performed. The ETON module and the evaluation process were facilitated by a group of ophthalmologists.

Results: There was a significant difference in the post-intervention knowledge scores for the treatment group $(M=9.27, S D=2.191)$ and control group ( $M=7.27, S D=3.121)$ conditions; $t(34)=2.22, p=0.03$. No quantifiable change in attitudes between groups was assessed at the time of intervention. There was a significant difference in the increase in practice scores for the treatment group prior to intervention $(M=28.3, S D=12.169)$ and post-intervention $(M=56, S D=10.53)$ conditions; $t(34)=-7.30631, p<0.0000001$, and there was also significant difference in the increase in practice scores for the control group prior to intervention $(M=22.3, S D=5.45)$ and post-intervention $(M=45.9, S D=17.031)$ conditions; $t(34)=-7.30$, $\mathrm{p}<0.0000001$. With regard to the implementation of the OSCE, it can be noted that participants from both groups scored least in obtaining the correct Best Corrected Visual Acuity (BCVA) and scored most in straight-forward types of eye-screening tests such as Ishihara Color Vision Test and Amsler Grid. This research showed that participants under the treatment group performed significantly better than the control group.

Conclusion: The ETON Module can be used to improve the standard of care by extending access to visual health services by building the capacities of primary health workers to be a reliable referral pivot point in monitoring ETON among TB patients. This study can be used as a foundation to initiate an expanded primary health services to improve the visual health outcomes for TB patients.

Keywords: Ethambutol; Optic neuropathy; Tuberculosis

\section{Introduction}

The Philippines is one of the highest tuberculosis burdened countries in the world. Currently, the Philippines is 8th among the twenty-two (22) tuberculosis high-burden countries in the world in terms of tuberculosis cases. In 2015, World Health Organization (WHO) reported tuberculosis has an incidence of $322 / 100,000$ and a mortality rate of $13 / 100,000$ per population in the country
[1]. The Department of Health (DOH) also reported that there is a marked decline in tuberculosis burden since the launching of the Directly Observed Treatment Short Course (DOTS) strategy in 1996. Cases and deaths due to tuberculosis were reduced by more than fifty (50) percent from the 1990 baseline [2]. However, it is noted that the program lacks guidelines specifically addressing the identification, record keeping, prevention and management 
of possible unwanted visual effects of taking anti-tuberculosis medications [3].

Ethambutol has been used to treat tuberculosis since 1960s. The potential for visual impairment was recognized soon after its introduction [4]. The visual loss in ethambutol toxic optic neuropathy is typically relatively symmetrical, with a subacute onset usually commencing 2 to 8 months after initiation of treatment. There is variability at the onset of ethambutol toxic optic neuropathy as reported in a meta-analysis of 70 cases, whereas the shortest duration of therapy prior to onset of symptoms was 3 days and the longest was 18 months [5].

According to the WHO Treatment of Tuberculosis Guidelines, the recommended dose of ethambutol for adults as a daily regimen is at $15 \mathrm{mg} / \mathrm{Kg} /$ day and as a thrice a week regimen at $30 \mathrm{mg} / \mathrm{Kg} /$ day [6].Several studies have been reported regarding the incidence of ethambutol toxic optic neuropathy in different countries [7-10]. In the literature, optic neuritis develops in $50 \%$ at a dose of $60 \mathrm{mg} /$ $\mathrm{Kg} /$ day and can even develop with the standard dosage [11]. In a meta-analysis done by Ezer et al, pooled cumulative incidence of any visual impairment in all patients was 22.5 per 1,000 persons treated with ethambutol, and permanent impairment was 4.3 per 1,000. Typically, vision loss was noted to be reversible once the drug is discontinued early [12]. In reversible cases, resolution of impairment occurred after an average of 3 Months [10]. Despite of this surmounting studies, there is still no available data regarding the incidence of ethambutol toxic optic neuropathy in the Philippines. The screening tests for ethambutol toxic optic neuropathy (ETON) are those that measure the functions of the optic nerve, specifically the papillomacular bundle. Good measurement of the optic nerve function includes visual acuity, color vision test, and central visual fields [13-17]. It has been reported that different color vision errors occur as an early signs of ethambutol toxic optic neuropathy in patient with normal acuity and no other visual symptoms. The Ishihara test is the most commonly used screening tool for color vision abnormalities. It is mainly useful in detecting congenital and acquired red-green deficiency. The more common visual field manifestation in ETON is a central or ceco central scotoma $[16,18$ 20].

The ETON module is a collaborative project between Ospital ng Maynila Medical Center Department of Ophthalmology, Manila Health Department and Neuro-ophthalmology Society of the Philippines. It is a module based on the recommended practices on identification, prevention and management of ethambutol toxic optic neuropathy by the Philippine Academy of Ophthalmology and Neuro-ophthalmology Society of the Philippines. Its primary function is to increase the knowledge, attitudes, and practices training of TB DOTS health workers on basic eye screening tests as an extension of National Tuberculosis TB Control Program service and strengthen the surveillance of visual disorders related to the administration of anti-tuberculosis medications. A monitoring and evaluation on the ETON module were conducted to assess how the system has helped the proficiency of health workers in rendering basic eye screening services to TB DOTS patients.

\section{Materials and Methods}

\section{Research design}

This study was designed using a randomized control-group pre-test and post-test design. In this design, there is randomization of study subjects to treatment and control groups. In essence, this design allowed the comparison of the relative effectiveness of supportive supervision delivered through ETON module with that of the IEC materials strategy. There were two measurements for each batch of training participants: baseline and immediately after training. This design allowed measurement of the immediate outcome of the training.

\section{Study sample population}

Thirty-six TB DOTS health workers were included by convenience sampling. These were randomly allocated into the treatment and control group. The treatment group whose members received the ETON module and supportive supervision by a neuro-ophthalmologist. The comparison group received only IEC materials.

\section{Measuring knowledge, attitudes and practices}

The performance areas evaluated include knowledge, attitudes, and practices on ETON and basic eye screening tests including

- Visual acuity testing

- $\quad$ Color vision testing

- $\quad$ Visual field testing

To answer the question on competency retention, a KAP questionnaire used by Dizon et al in 2013 and an objective structured clinical examination (OSCE) based on the topics covered were administered immediately post-training. The components of OSCE were

1. Best Corrected Visual Acuity,

2. Ishihara Color Vision Test,

3. Amsler Grid and

4. giving the Final Disposition if ophthalmology service referral is warranted.

Facilitated focus group discussions (FGD) were conducted postintervention to assess how the ETON screening module affected the health service providers' attitude and behavior towards skill performance.

\section{Statistical analysis}

Data based on results of the performance review was encoded and analyzed using the statistical software, IBM SPSS Statistics Subscription. Descriptive analyses included the calculation of the mean, median and mode of continuous variables while qualitative variables are presented as frequency distributions. KAP and OSCE mean scores before and after intervention for both groups were compared using the Student's t-test. 


\section{Results}

A total of thirty-six participants were included in the study and were randomly allocated into two groups. The groups had a similar number of representation of 18 participants per group. For those who were enrolled in the treatment group, the average age was 38.3 years, while in the control group, it was 42.1 years. TB DOTS nurses were generally female, about $77 \%$ of all the participants. It can be noted that baseline characteristics (i.e. age, sex, average number of years of TB DOTS practice, and average number of TB DOTS seminars attended) are similar between groups. Demographic data are reported in (Table 1 ).

Table 1: Baseline Characteristics of Local TB DOTS Nurses Enrolled in the ETON Module Program Evaluation.

\begin{tabular}{|c|c|c|c|c|}
\hline \multirow{2}{*}{ Demographic Characteristics } & \multicolumn{2}{|c|}{ Treatment Group (n=18) } & \multicolumn{2}{|c|}{ Control Group (n=18) } \\
\cline { 2 - 5 } & Mean & MD & 42.10 years & 8.37 \\
\hline Age & 39.80 years & & & \\
\hline Sex & & & $3(21.05 \%)$ & \\
\hline Male & $4(22.20 \%)$ & & $15(78.9 \%)$ & \\
\hline Female & $14(77.8 \%)$ & 0.71 & 10.50 years & 0.67 \\
\hline TB DOTS Experience & 9.50 years & 3.1 & 5.22 & 2.96 \\
\hline TB DOTS Seminars Attended & 5.43 & & & \\
\hline
\end{tabular}

\section{Knowledge, attitudes, practices}

Results measuring knowledge, attitudes, and practices are shown in Table 2. There was no significant difference in the knowledge scores prior to intervention for the treatment group $(\mathrm{M}=5.22, \mathrm{SD}=3.61)$ and control group $(\mathrm{M}=4.11, \mathrm{SD}=2.74)$ conditions; $\mathrm{t}(34)=1.039, \mathrm{p}=0.3061$. Another independent-samples t-test was conducted to compare mean scores of the treatment group and of the control group after administering the respective interventions. There was a significant difference in the knowledge scores after ETON module implementation for the treatment group ( $M=9.27$, $\mathrm{SD}=2.191)$ and control group $(\mathrm{M}=7.27, \mathrm{SD}=3.121)$ conditions; $\mathrm{t}$ $(34)=2.22, p=0.03$ (Table 2).

Table 2: Mean Knowledge, Attitudes, and Practices Scores of Participants from Treatment and Control Groups Before and after Intervention.

\begin{tabular}{|c|c|c|c|c|}
\hline \multirow{2}{*}{$\begin{array}{c}\text { Performance } \\
\text { Area }\end{array}$} & \multicolumn{2}{|c|}{ Treatment Group } & \multicolumn{2}{c|}{ Control Group } \\
\cline { 2 - 5 } & Mean Score Pre-Intervention & Mean Score Post-Intervention & Mean Score Pre-Intervention & Mean Score Post-Intervention \\
\hline Knowledge & $5.22(\mathrm{SD}=3.61)$ & $9.27(\mathrm{SD}=2.19)$ & $4.11(\mathrm{SD}=2.74)$ & $7.27(\mathrm{SD}=3.12)$ \\
\hline Attitudes & $13.2(\mathrm{SD}=2.15)$ & $13.9(\mathrm{SD}=1.83)$ & $13(\mathrm{SD}=3)$ & $14(\mathrm{SD}=1)$ \\
\hline Practices & $28.3(\mathrm{SD}=12.17)$ & $56(\mathrm{SD}=10.53)$ & $22.9(\mathrm{SD}=5.45)$ & $45.9(\mathrm{SD}=17.03)$ \\
\hline
\end{tabular}

Attitudes were described through a Likert type of scoring system using a 3-Item Questionnaire. Attitudes were analyzed as scores, a continuous variable. There was no significant difference in the decrease in attitude scores for the treatment group prior to intervention $(\mathrm{M}=13.9, \mathrm{SD}=2.15)$ and post-intervention $(\mathrm{M}=13.2$, $\mathrm{SD}=1.83$ ) conditions; $\mathrm{t}(34)=1.05188, \mathrm{p}=0.3$. Another $\mathrm{t}$-test was performed to know if the change in the mean scores of the control group post-intervention was significant. There was no significant difference in the increase in attitude scores of the control group prior to intervention $(M=13, S D=2)$ and post-intervention $(M=14$, $\mathrm{SD}=1$ ) conditions; $\mathrm{t}(34)=\mathrm{p}=0.03$.

Practices assumed by the treatment group prior to the ETON Module were described using a 12-Item Questionnaire. Results show an increase in the percentages that represents practices after undergoing the ETON Module. Practices were analyzed as scores, a continuous variable. There was a significant difference in the increase in practice scores for the treatment group prior to intervention $(M=28.3, S D=12.169)$ and post-intervention $(M=56$, $\mathrm{SD}=10.538$ ) conditions; $\mathrm{t}(34)=-7.30631, \mathrm{p}<0.0000001$. Another t-test was performed to know if the change in the mean scores of the control group post-intervention was significant. There was a significant difference in the increase in practice scores for the control group prior to intervention $(M=22.3, S D=5.4545$ and post-intervention $(\mathrm{M}=45.94444, \mathrm{SD}=17.031)$ conditions; $\mathrm{t}$ (34) $=-7.30631, \mathrm{p}<0.0000001$.

\section{Objective structured clinical examination}

An OSCE on Eye Screening Tests was done to test both groups' retention on the expected skills they have learned from the ETON Module and the IEC materials. Table 3 shows the performance scores under the following parameters:

- $\quad$ Best Corrected Visual Acuity

- Ishihara Color Vision Test

- Amsler Grid and giving the

- Final Disposition

(Table 3)

Table 3: Mean OSCE Scores of Participants from Treatment and Control Groups after Intervention.

\begin{tabular}{|c|c|c|}
\hline & Treatment Group & Control Group \\
\hline Performance Area & $\begin{array}{l}\text { Mean Score Pre- } \\
\text { Intervention }\end{array}$ & $\begin{array}{l}\text { Mean Score Pre- } \\
\text { Intervention }\end{array}$ \\
\hline Visual Acuity & $13.0(\mathrm{SD}=8.60)$ & $9.0(\mathrm{SD}=10.44)$ \\
\hline Ishihara Color Vision Test & $17.6(\mathrm{SD}=0.57)$ & $13.0(\mathrm{SD}=4.5)$ \\
\hline Amsler Grid & $17.8(\mathrm{SD}=0.44)$ & $16.8(\mathrm{SD}=1.643)$ \\
\hline Final Disposition & $16.6(\mathrm{SD}=3.13)$ & $16.4(\mathrm{SD}=2.5)$ \\
\hline
\end{tabular}


The difference in mean scores in visual acuity testing between the treatment group $(M=13, S D=8.60)$ and the control group $(M=9$, $\mathrm{SD}=10.44)$ is not statistically significant $(\mathrm{t}=1.25466, \mathrm{p}=0.4323)$, although a difference of about $30 \%$ can be appreciated. The difference in mean scores in Ishihara plate color vision testing between the treatment group $(\mathrm{M}=17.6, \mathrm{SD}=0.57)$ and the control group $(M=13, S D=4.5)$ is also statistically significant $(t=4.30254$, $\mathrm{p}<0.00001$ ) The difference in mean scores in Amsler Grid testing between the treatment group $(\mathrm{M}=17.8, \mathrm{SD}=0.44)$ and the control group $(M=16.8, S D=1.643)$ is statistically significant $(t=2.48$, $\mathrm{p}<0.005$ ). In giving the final disposition whether an ophthalmology service referral is warranted or not, given the clinical circumstances of the cases, the difference in mean scores in giving the final disposition between the treatment group ( $M=16.6, S D=3.13)$ and the control group ( $M=16.4, S D=2.5)$ is not statistically significant $(\mathrm{t}=0.2118, \mathrm{p}=0.3632)$.

\section{Discussion}

Evidence suggests that most of the anti-tuberculosis medications can cause toxic optic neuropathy, ethambutol being the most notorious of this adverse effect. Despite sufficient evidence on ETON, our health program on tuberculosis control lack provisions in preventing this dreaded adverse effect. It should be emphasized that ethambutol toxic optic neuropathy is a reversible disease. A delayed recognition of this disease could mean bilateral irreversible blindness to affected patients. Simple eye screening tests like visual acuity testing, color vision testing or central visual field testing may be adequate to make a difference in affected patients. Preintervention poor knowledge scores suggest that although the participants are trained TB DOTS staff with adequate seminars attended, ETON as an essential part of TB DOTS health service was not discussed adequately. The participants were amenable toward visual health screening for the TB DOTS patient. The health workers acknowledge that there is a need for the eye screening prior and upon anti- tuberculosis treatment. Practices confirmed that the recommended clinical practice guideline on visual health monitoring among TB patients is not being implemented. The effectivity of the interventions are confirmed by the increase in knowledge and practices both from the ETON module and IEC only groups. Attitudes remained high post intervention. Although both groups improved, it should be noted that the ETON module group significantly increased in proficiency compared to IEC only group.

With regard to the implementation of the OSCE, it can be noted that participants from both groups scored least in obtaining the correct Best Corrected Visual Acuity (BCVA) and scored most in straight-forward types of eye-screening tests such as Ishihara Color Vision Test and Amsler Grid. It was noted that although both groups scored least in obtaining the BCVA, the treatment group scored relatively higher than the control group. The reason for this may be due to the fact that assessing the visual acuity of a patient requires repetition and supportive guidance from an ophthalmologist. Despite not being able to obtain the correct BCVA of the patient, with the guidance of two other tests namely the Ishihara Color Vision Test and the Amsler Grid, most of the participants from both groups were able to reach the proper final disposition. A positive result from at least one of the 3 screening tests would be sufficient to reach a final disposition to refer a patient for further evaluation and management of ETON, hence a high score for the category of final disposition. Although, it should not be underscored that a better accuracy in performing the tests are valuable in detecting subtle changes in optic nerve functions, thus enabling early recognition of a possible toxic optic neuropathy.

With regard to the acceptability of the program to the participants, the participants provided a generally positive rating to both the program content and facilitators. During the feedback session, they requested a follow-up training with a longer program time and less compressed topics in at least one training day.

\section{Limitations}

Although a small sample was used to conduct this pilot study, participants were from the city of Manila which allowed an adequate sample of health workers in TB DOTS centers. The findings of this study confirm that there is no visual health program implemented in our TB DOTS centers. The questionnaire for the practices post intervention were made in a futuristic manner, hence, the results can be an overestimation of what would have been done in the real clinical setting. No pre-intervention OSCE was done, hence, a pretest and post-test comparison for OSCE is not part of this study. Another limitation includes the limited time for the participants to learn the ETON module. Due to a limited permitted time to have the participants, the ETON module and OSCE was done in a span of half day. Probably a longer time to teach the module will provide better retention and outcome.

\section{Conclusion}

This study determined the effectiveness and practical use of the ETON Module in increasing the competency of health workers in providing basic eye screening tests to TB DOTS patients. The ETON Module can be used to improve the standard of care by extending access to visual health services by training our primary health workers to be a reliable referral pivot point in monitoring ETON among TB patients. This study can be used as a foundation to initiate an expanded primary health services to improve the visual health outcomes for TB patients.

\section{Recommendations}

A longitudinal study may be conducted to investigate the level of retention of knowledge, attitudes, and practices acquired through this type of training. A longer duration of training and follow-up training on ETON should be done to facilitate a more comprehensive sharing of knowledge, experiences and skills and also increase long term retention of information.

\section{Acknowledgements}

None.

\section{Conflicts of Interest}

No conflict of interest. 


\section{References}

1. World Health Organization (2016) Global Tuberculosis Report.

2. Philippine Coalition Against Tuberculosis (2016) Clinical Practice Guidelines for the Diagnosis, Treatment, Prevention and Control of Tuberculosis in Adult Filipinos 2016 Update. Philippine.

3. Richard C Kho (2010) The scourge of ethambutol-related toxic optic neuropathy in the Philippines. Philippine Academy of Ophthalmology 35(1): 1-2.

4. Solanki Roshni, Dhaval Madat, Chauhan Khushbu, Adeshara Subodh (2011) An overview on optic neuritis. International Research Journal of Pharmacy 2(5): 49-53.

5. Talbert K, Sadun A (2010) Risks factors for ethambutol optic toxicity. Int Ophthalmol 30(1): 63-72.

6. WHO (2010) Treatment of Tuberculosis Guidelines Fourth Edition. Russia.

7. Lv X, Tang S, Xia Y, Wang X, Yuan Y, et al. (2013) Adverse Reactions Due to Directly Observed Treatment Strategy Therapy in Chinese Tuberculosis Patients: A Prospective Study. PLoS ONE 8(6): e65037.

8. Lee EJ, Kim SJ, Choung HK, Kim JH, Yu YS (2008) Incidence and Clinical Features of Ethambutol-Induced Optic Neuropathy in Korea. J NeuroOphthalmol 28(4): 269-277.

9. Shih Chou Chen, Muh Chiou Lin, Shwu Jiuan Sheu (2015) Incidence and prognostic factor of ethambutol-related optic neuropathy: 10-year experience in southern Taiwan. Kaohsiung J Med Sci (2015) 31(7): 358362.
10. N Ezer, A Benedetti, M Darvish Zargar, D Menzies (2013) Incidence of ethambutol-related visual impairment during treatment of active tuberculosis. Int J Tuberc Lung Dis 17(4): 447-455.

11. Su Ann Lim (2006) Ethambutol-associated Optic Neuropathy. Ann Acad Med Singapore 35(4): 274-278.

12. RaghuV, Rajender M, Kiran Beesam, Nithin Reddy, et al. (2016) A prospective evaluation of visual function for early detection of ethambutol toxicity. MRIMS Journal of Health Science 4(2): 89-92.

13. Rose A Tang, Jade Schiffman, Roberto Alejandro Cruz, Gabriela Corsi (2014) Ethambutol: friend or foe? Expert Review of Ophthalmology 9(2): 59-61.

14. Tuano Prospero Ma (2008) The challenges of ophthalmic residency education in the Phils. Philipp J Ophthalmol 33(2): 70-80.

15. Alfredo A Sadun, Michelle Y Wang (2008) Ethambutol Optic Neuropathy: How We Can Prevent 100,000 New Cases of Blindness Each Year. J Neuro-Ophthalmol 28(4): 265-268.

16. Richard C Kho (2004) The eye on neuro-ophthalmology. PJO 29(4): 159.

17. Cruz E, Puentespina F, Alejo KP, Morabe E, Nanagas ML (2010) Colorvision abnormalities among patients undergoing tuberculosis treatment. Phillip J Ophthalmol 35(1): 3-9.

18. Griffith, Brown Elliot, Shepherd (2005) Ethambutol Ocular Toxicity in MAC Disease. Am J Respir Crit Care Med 172: 250-253.

19. Pradeep Sharma, Reena Sharma (2011) Toxic optic neuropathy. Indian J Ophthalmol 59(2): 137-141.

20. Makunyane P, Mathebula S (2016) Update on ocular toxicity of ethambutol. Afr Vision Eye Health 75(1). 